Note: This is a preprint of an abstract being submitted for publication. Contents of this paper should not be quoted nor referred to without permission of the author(s)

To be Published in: CONF-96/202--9

Nanophase and Nanocomposite Materials II

Editors: S. Komarneni, J. C. Parker, \& H. J. Wollenberger

Proceedings of the MRS 1996 Fall Meeting, Boston, MA, Dec. 2-6, 1996

\title{
The Formation of Metal/Metal-Matrix Nano-Composites by the Ultrasonic Dispersion of Immiscible Liquid Metals
}

\author{
V. M. Keppens ${ }^{1}$, D. Mandrus ${ }^{1}$, J. Rankin ${ }^{2}$, and L. A. Boatner ${ }^{1}$ \\ ${ }^{1}$ Solid State Division, Oak Ridge Nat'l Lab., Oak Ridge, TN 37831-6056, (USA) \\ ${ }^{2}$ Division of Engineering, Brown University, Providence, RI 02912, (USA)
}

December 1996

\begin{abstract}
"The submitted manuscript has been authored by a contractor of the U.S. Government under contract No. DE AC05-96OR22464. Accordingly, the U.S. Government retains a nonexclusive, royalty-free license to publish or reproduce the published form of this contribution, or allow others to do so, for U.S. Government purposes."
\end{abstract}

prepared by

Solid State Division

Oak Ridge National Laboratory

P.O. Box 2008

Oak Ridge, Tennessee 37831-6056

managed by

LOCKHEED MARTIN ENERGY RESEARCH CORP.

for the

U.S. DEPARTMENT OF ENERGY

under contract DE-AC05-96OR22464

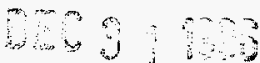

से का

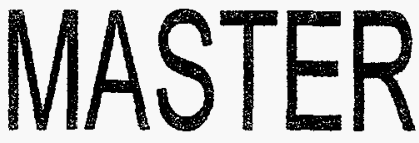




\section{DISCLAIMER}

This report was prepared as an account of work sponsored by an agency of the United States Government. Neither the United States Government nor any agency thereof, nor any of their employees, makes any warranty, express or implied, or assumes any legal liability or responsibility for the accuracy, completeness, or usefulness of any information, apparatus, product, or process disclosed, or represents that its use would not infringe privately owned rights. Reference herein to any specific commercial product, process, or service by trade name, trademark, manufacturer, or otherwise does not necessarily constitute or imply its endorsement, recommendation, or favoring by the United States Government or any agency thereof. The views and opinions of authors expressed herein do not necessarily state or reflect those of the United States Government or any agency thereof. 


\section{DISCLAIMER}

Portions of this document may be illegible in electronic image products. Images are produced from the best available original document. 


\title{
THE FORMATION OF METAL/METAL-MATRIX NANOCOMPOSITES BY THE ULTRASONIC DISPERSION OF IMMISCIBLE LIQUID METALS
}

\author{
V. KEPPENS*, D. MANDRUS*, J. RANKIN**, L.A. BOATNER* \\ *Oak Ridge National Laboratory, Solid State Division, P.O. Box 2008, MS 6056, Oak Ridge TN \\ 37831-6056,vk1@ornl.gov \\ **Brown University, Box D, 182 Hope St., Providence RI 02912
}

\begin{abstract}
Ultrasonic energy has been used to disperse one liquid metallic component in a second immiscible liquid metal, thereby producing a metallic emulsion. Upon lowering the temperature of this emulsion below the melting point of the lowest-melting constituent, a metal/metal-matrix composite is formed. This composite consists of sub-micron-to-micron-sized particles of the minor metallic phase that are embedded in a matrix consisting of the major metallic phase. The zinc-bismuth case was used as a model system, and ultrasonic dispersion of a minor bismuth liquid phase was used to synthesize metal/metal-matrix composites. These materials were subsequently characterized using scanning electron microscopy and energy-dispersive $\mathrm{x}$-ray analysis.
\end{abstract}

\section{INTRODUCTION}

The special properties that can be obtained by forming metal-matrix composites have previously been extensively documented. While much of the prior attention given to these materials has been focused on metal matrices reinforced with ceramic particles or fibers [1], the results reported for metal/metal-matrix composites show that the latter are no less interesting. For example, a new class of metal/metal matrix materials has been developed that exhibits extraordinary mechanical properties $[2,3,4]$. These materials are composed of a mixture of $\mathrm{Cu}$ plus $10-30 \%$ of a metal $\mathrm{X}$ that is immiscible with $\mathrm{Cu}$. The mixture is severely deformed to produce a nanometer-scale microstructure of immiscible $\mathrm{X}$ filaments (or lamellae) within the $\mathrm{Cu}$ matrix. Such processed composites have a strength that is substantially higher than those reported for any traditional $\mathrm{Cu}$ alloy.

In efforts to improve the mechanical properties - in particular the hardness - of materials, Singh et al. have dispersed approximately $20 \mathrm{wt} . \% \mathrm{Bi}$ in $\mathrm{Zn}$, using a melt-spinning technique [5]. This technique produced a metal/metal-matrix composite of nanosized Bi spheres entrained in a $\mathrm{Zn}$ matrix where the size of the Bi particles was controlled by adjusting the wheel speed used in the melt-spinning process. Hardness measurements performed on these materials showed that a decrease in the size of the Bi nanodispersoids leads to an increase in hardness.

In the present work, a new approach to the formation of bulk metal/metal-matrix composites is presented. High-intensity ultrasound has been used to disperse one metallic liquid in a second immiscible liquid metal thereby forming a metallic emulsion. When this emulsion is cooled, a metal/metal-matrix composite is formed consisting of minor-phase particles dispersed in the solidified major phase.

The basic idea of using ultrasound for mixing immiscible liquids is, of course, not new. In 1926, Wood and Loomis [6] reported that if two immiscible liquids such as oil and water are simultaneously subjected to ultrasonic radiation, an emulsion or colloidal suspension is formed as 
a result of the forces acting at the interface between the liquids. A further extensive study of the mechanism of emulsification and coagulation by ultrasonic waves in water-oil and mercurywater/organic liquid systems was carried out by Bondy and Söllner [7,8].

A previous study of the influence of ultrasound on the production of unusual metallic mixtures was described by Schmidt and Ehret [9] and Schmidt and Roll [10]. Part of their work focused on the dispersion of $35 \mathrm{wt} \% \mathrm{~Pb}$ in $\mathrm{Al}$. By applying ultrasound with a frequency of 10 $\mathrm{kHz}$ to the melt, the $\mathrm{Pb}$ phase could be dispersed, forming spherical inclusions with a diameter of approximately $30 \mu \mathrm{m}$ embedded in the Al matrix. However, the mixing of the components was incomplete, and a significant residue of $\mathrm{Pb}$ was found at the bottom of the crucible. More recently, a group in China has reported the use of ultrasound for the preparation of fine ceramicparticulate-reinforced metal-matrix composites [11] in which high-intensity ultrasound was used to disperse micrometer-size ceramic particles homogeneously in an aluminum matrix.

\section{EXPERIMENTAL PROCEDURE}

In order to investigate the application of ultrasound to the formation of metal $/ \mathrm{metal}$ matrix composites, the $\mathrm{Zn}-\mathrm{Bi}$ case was selected as a model system, since both metals are relatively easy to handle based on their chemical reactivity and low melting points. Additionally, the wide miscibility gap in the $\mathrm{Zn}-\mathrm{Bi}$ phase diagram (See Figure 1) made this system a particularly attractive candidate for the ultrasonic formation of metallic emulsions in varying concentrations.

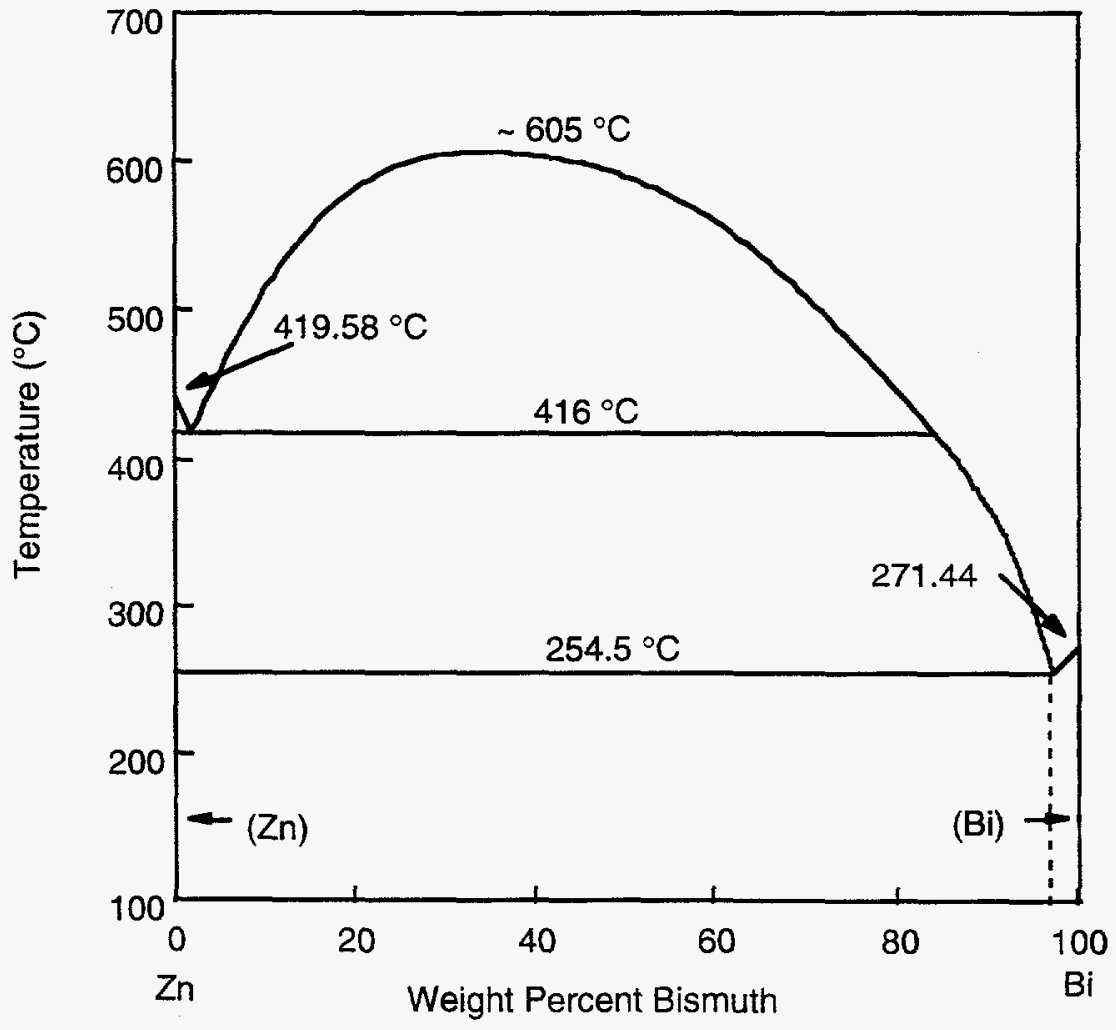

FIGURE 1: Equilibrium phase diagram of the $\mathrm{Zn}-\mathrm{Bi}$ system showing the wide miscibility gap characteristic of this system [12]. 
The uitrasonic source used in the present experiments was a Misonix Sonicator Model W-385 that consists of a generator which feeds $20 \mathrm{kHz}$ electrical energy to a transducer where it is transformed to mechanical vibrations. The ultrasonic energy is generated by a transducer that consists of a lead zirconate titanate piezoelectric driver. When subjected to an alternating applied voltage, this piezoelectric material expands and contracts at the $20 \mathrm{kHz}$ driving frequency. The transducer is mechanically coupled to an acoustically resonant Ti-alloy horn assembly that vibrates in a longitudinal direction and transmits the high-frequency motion to the horn tip. A highly tapered Ti horn (termed a microtip) was used to achieve high-amplitude ultrasonic vibrations. A schematic representation of the ultrasonic processing system is shown in Figure 2.

The $\mathrm{Zn}-\mathrm{Bi}$ composition selected for the present experiments consisted of $10 \mathrm{wt} \% \mathrm{Bi}$. Once the two metals were weighed to achieve the appropriate proportions, they were then melted in a $\mathrm{SiO}_{2}$ tube using a propane torch and were heated to approximately $650^{\circ} \mathrm{C}$. To minimize oxide-formation, argon gas containing $4 \% \mathrm{H}_{2}$ was continuously sprayed over the surface. When the desired melt temperature was reached, the torch was turned off and the sonication process was initiated by immersing the vibrating microtip in the liquid. While the Tialloy used for the horn and tip represents the best horn material from the mechanical and acoustic point of view - combining outstanding acoustic properties with lightness, strength, abrasion resistance and chemical inertness - it tends to form an alloy with the $\mathrm{Zn}$-phase. This interaction results in degradation of the microtip when it is immersed in the melt. Accordingly, in order to minimize the reaction of the Ti-tip with the sample, the sonication process had to be limited to short durations - typically 10-30 seconds. In the present experiments, the melt is first sonicated for $10-15$ seconds while it begins cooling down at a typical cooling rate of $10^{\circ} \mathrm{C}$ per second. The solidification process is subsequently accelerated by spraying water on the outside of the $\mathrm{SiO}_{2}$ tube, while maintaining the sonication conditions, until the solidification is complete. This results

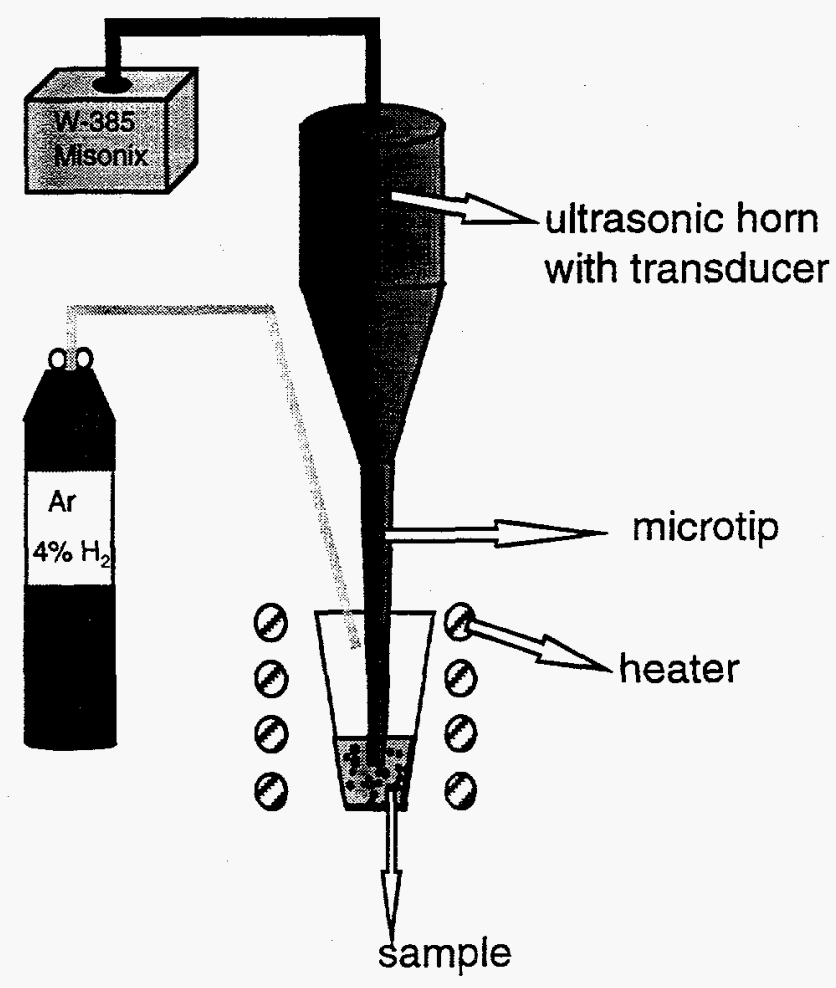

FIGURE 2: Schematic representation of the uitrasonic system. 
in a total sonication time of $20-30$ seconds. The resulting composite samples were then polished to obtain a flat surface suitable for examination in the scanning electron microscope.

\section{EXPERIMENTAL RESULTS AND DISCUSSION}

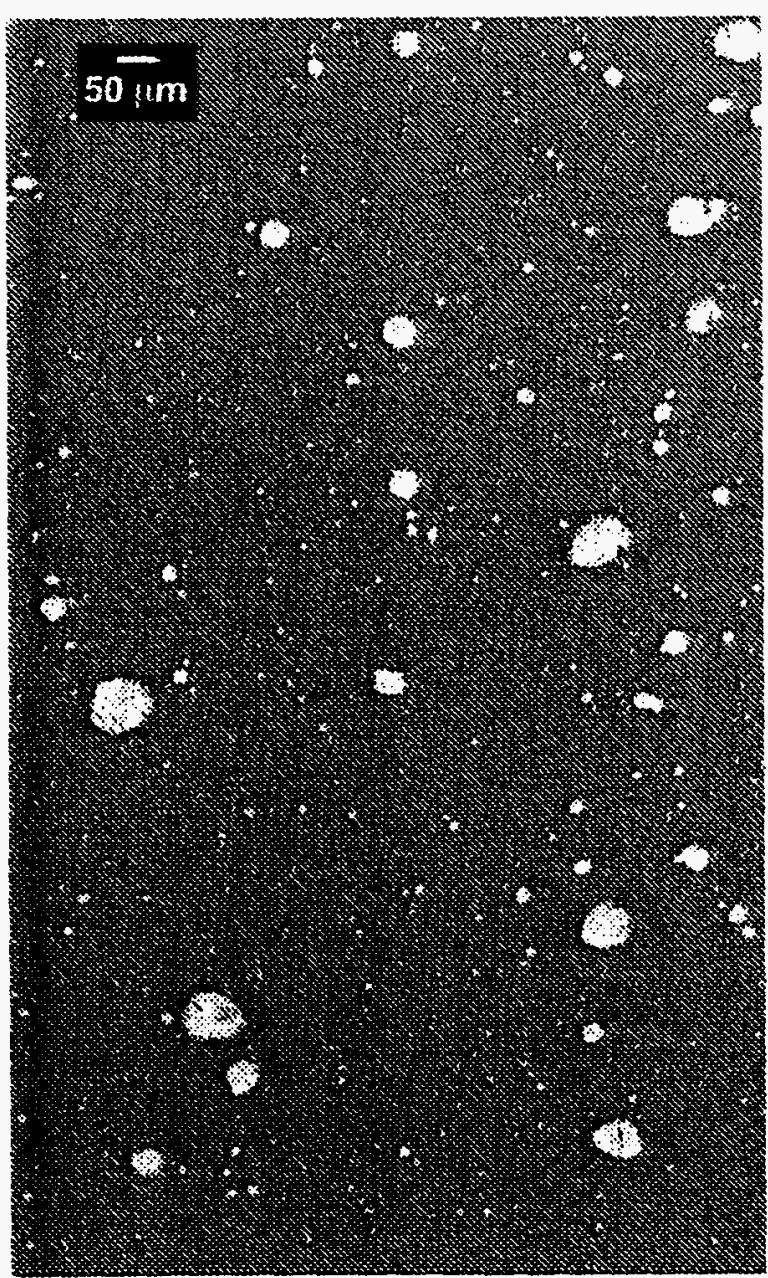

(a)

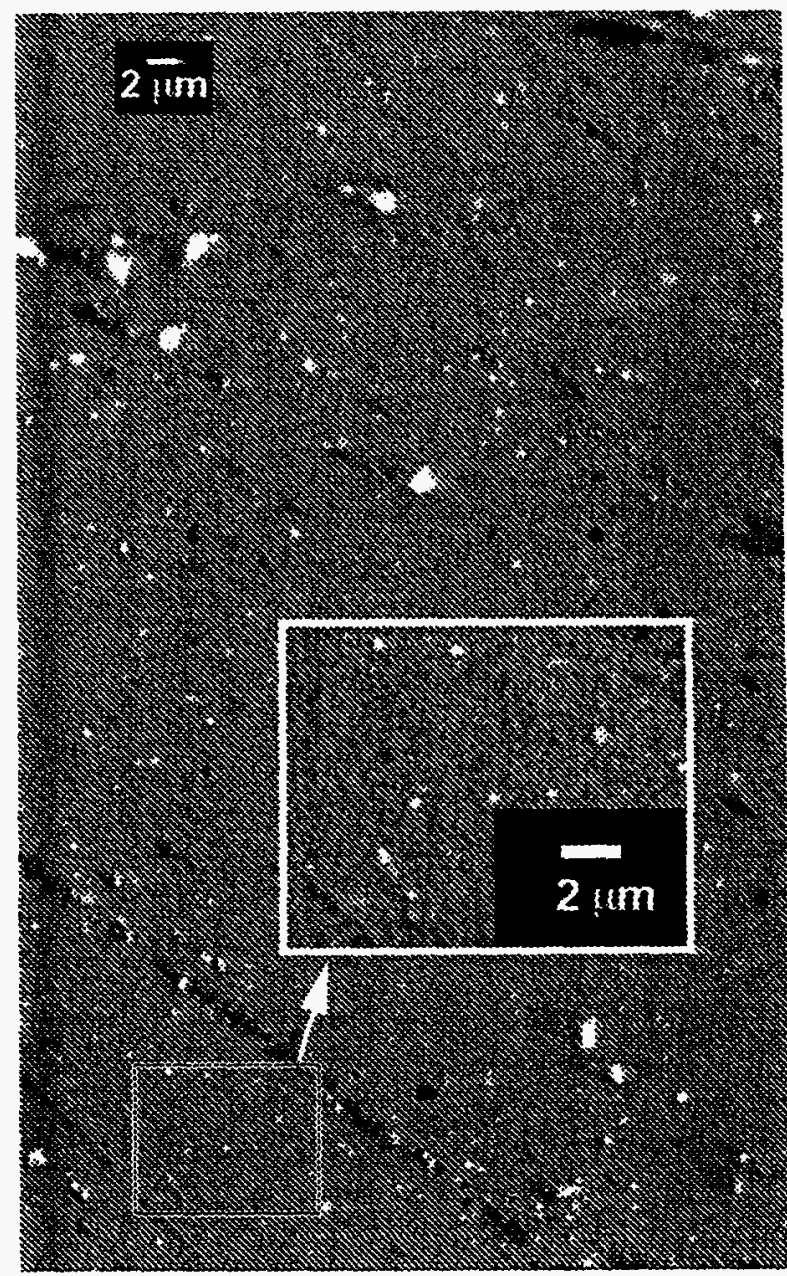

(b)

FIGURE 3 (a) and (b): SEM image of a $\mathrm{Zn}-\mathrm{Bi}$ composite obtained by sonication of the two molten immiscible liquid metals.

Figure 3(a) shows an SEM image of a composite metal/metal-matrix sample obtained after the sonication of a $\mathrm{Zn}$ plus $10 \mathrm{wt} \% \mathrm{Bi}$ melt. Energy Dispersive $\mathrm{X}$-ray analysis (EDX) confirms that the light colored dispersed particles are $\mathrm{Bi}$, while the gray background consists of $\mathrm{Zn}$. As evident in the micrograph, the $\mathrm{Bi}$ phase forms essentially spherical particles that are embedded in the $\mathrm{Zn}$-matrix. This dispersion is, however, far from homogeneous: Figure 3(a) clearly shows $\mathrm{Bi}-$ particles with diameters ranging from more than $50 \mu \mathrm{m}$ to less than $5 \mu \mathrm{m}$. Additionally, significantly smaller particles with diameters below $0.5 \mu \mathrm{m}$ can be detected, as revealed in Figure 3(b). The presence of these sub-micron particles of $\mathrm{Bi}$ indicates that the application of highintensity ultrasound can be a powerful tool for the formation of nanocomposite materials through 
the creation of metallic emulsions. However, it is clear from the observed microstructures that the major problem to be overcome in order to obtain uniform materiais is achieving a marked improvement in the monodispersed size-distribution of the minor-phase particles.

In order to gain insight as to how metal/metal-matrix composites with a moremonodispersed minor phase can, in fact, be achieved by ultrasonic dispersion methods, a better understanding of the operative mechanisms responsible for the dispersion and the various parameters that control these mechanisms is needed. While previous investigations $[6,7,8]$ have clearly shown that sonication of a liquid or melt significantly influences its behavior, there is, at present, no general consensus regarding the exact nature of the operative ultrasonic mechanism. According to Bondy and Söllner $[7,8]$, the emulsification of immiscible liquids is due to the collapse of acoustic cavitation bubbles. Here "cavitation" refers to the formation, growth, and collapse of bubbles in liquids[13] that are initiated at nucleation sites where the tensile strength of the liquid is dramatically lowered -e.g., at small trapped gas bubbles. When sound passes through the liquid, these bubbles oscillate as a result of the rapid expansion and compression waves created by the sound field. As the bubble oscillates, it grows through several mechanisms and finally collapses catastrophically. When cavitation takes place near an interface, major changes in the nature of the bubble collapse occur. A markedly asymmetric collapse happens that generates a jet of liquid directed at the interface. This liquid jet may thus represent a mechanism for the injection of one liquid phase in the other. An other concept for the emulsification of immiscible liquids that does not involve cavitation has been presented by Suslick [14]. According to this model, ultrasonic compression and expansion effectively "stress" the liquid surfaces -eventually overcoming the cohesive forces that hold large droplets together. The larger droplets eventually burst into smaller droplets, and the liquids are thus emulsified.

Given the current lack of an accepted and appropriate model for the ultrasonic emulsification of liquids, an empirical investigation involving systematic variations of the ultrasonic parameters employed in the processing of a specific model system such as $\mathrm{Zn}-\mathrm{Bi}$ is indicated. For a $\mathrm{Zn}-\mathrm{Bi}$ sample with a fixed $\mathrm{Bi}$ concentration, three main parameters control the sonication process. These are: (1) the intensity of the applied ultrasound, (2) the sonicationtime, and (3) the temperature of the melt as subjected to the ultrasound. Experiments are presently underway to explore the effects of variations of these important parameters in the case of the emulsification of $\mathrm{Zn}-\mathrm{Bi}$ mixtures. In the case of experiments designed to explore increased time for ultrasonic processing, as noted earlier, the Ti-alloy used here for the ultrasonic horn tip reacts with $\mathrm{Zn}$. Therefore, it has been necessary to keep the sonication time short and the temperature of the melt relatively low in order to minimize melt/tip interactions.. In an attempt to avoid this limitation, some preliminary experiments have been carried out with a stainless steel tip. The first results show no indications of a reaction between the tip and the melt, and this system will be utilized in future experiments carried out for the purpose of exploring the effects of variations in the parameters noted above on the emulsification of immiscible liquid metals.

\section{CONCLUSION}

The present investigations have shown that high-intensity ultrasound can be effectively used to disperse one liquid metallic component into another thereby forming metal/metal-matrix composites. In the case of the $\mathrm{Zn}-\mathrm{Bi}$ system, the composite material consists of essentially spherical particles of $\mathrm{Bi}$ embedded in a $\mathrm{Zn}$ matrix. Dispersed nanophase $\mathrm{Bi}$ particles with diameters below $0.5 \mu \mathrm{m}$ can be formed, however, the overall distribution of the size of the dispersed $\mathrm{Bi}$ phase is rather broad. Future investigations will, therefore, focus on new methods 
for more effectively controlling the size distribution of the minor metallic phase particles formed by ultrasonic dispersion techniques. Additionally, the resulting metal/metal-matrix $\mathrm{Zn}-\mathrm{Bi}$ composite specimens will be characterized in terms of their physical, electronic, and mechanical properties and techniques for extending this general ultrasonic dispersal approach to higher melting point immiscible metals will be investigated.

\section{ACKNOWLEDGMENTS}

It is our pleasure to acknowledge the help of J. A. Kolopus, M. J. Gardner and D. W. Coffey. This work was supported in part by a grant from N.A.T.O and from the Fulbright Program, and by the Division of Materials Sciences, U.S. Department of Energy under contract DE-AC05960R22464 with Lockheed Martin Energy Research, Inc.

\section{REFERENCES}

1. For a review, see I. A. Ibrahim, F. A. Mohamed, and E. J. Lavernia, J. Mater. Sci.

2. J. Bevk, J. P. Harbison, and J. L. Bell, Appl. Phys. 49, 6031 (1978).

3. D. Verhoeven, F. A. Schmidt, E. D. Gibson and W. A. Spitzig, J. Metals 38, 20 (1986).

4. D. Verhoeven, F. A. Schmidt, L. L. Jones, H. L. Downing, C. L. Trybus, E. D. Gibson, L. S. Chumbley, L. G. Fritzmeier, and G. D. Schnittgrund, J. Mater. Eng. 12, 127 (1990).

5. B. Singh, R. Goswami, and K, Chattopadhyay, Scripta Metall. Mater. 28, 1507 (1993).

6. W. Wood and A. L. Loomis, Phil. Mag. S.7. 4, 417 (1927).

7. C. Bondy and K. Söllner, Trans. Faraday Soc. 32, 556 (1936).

8. K. Söllner and C. Bondy, Trans. Faraday Soc. 32, 616 (1936).

9. G. Schmidt and L. Ehret, Zeitschr. Elektrochem. 43, 869 (1937).

10. G. Schmidt and A. Roll, Zeitschr. Elektrochem. 45, 769 (1939); 46, 653 (1939).

11. L. Ma, F. Chen, 1. Shu, J. Mater. Sci. Lett. 14, 649 (1995).

12. Hansen, Constitution of Binary Alloys, 2nd ed. (McGraw-Hill Book Company, New York, 1958).

13. H. G. Flynn in Physical Acoustics, edited by W. P. Mason (Academic Press, New York, 1964), 1B, p. 57.

14. K. S. Suslick, Scientific American 260, 80 (1989). 